\title{
A NEGOCIAÇÃO COLETIVA E ASSÉDIO MORAL NO BRASIL: ALGUMA LUZ NO FIM DO TÚNEL? ${ }^{1}$
}

\author{
Rafael Maia Nogueira ${ }^{2}$ \\ Antônio Moreira de Carvalho Neto $^{3}$ \\ Thiago Soares Nunes ${ }^{4}$
}

http://dx.doi.org/10.1590/1413-2311.215.81936

\section{RESUMO}

A atuação sindical em relação ao assédio moral no trabalho, embora tímida, tem se intensificado ao longo das últimas décadas decorrente da degradação das condições laborais e adoecimento do trabalhador, pressionado pelo atual sistema econômico e social de competitividade. O artigo objetivou investigar como o assédio moral tem sido colocado dentro dos acordos e convenções coletivas de trabalho. Trata-se de uma pesquisa qualitativa e descritiva. Os dados utilizados na pesquisa foram coletados no banco de dados do Departamento Intersindical de Estatística e Estudos Socioeconômicos (DIEESE), que consistem em 177 cláusulas específicas que versam sobre assédio moral no período compreendido entre 2011 e 2016. Para análise dos dados, foi utilizado a análise de conteúdo, de acordo com sete categorias de análise. O quantitativo de cláusulas é relativamente pequeno se considerado o universo de entidades sindicais filiadas ao Departamento, mas pode-se observar uma pequena evolução no quantitativo de cláusulas no período, que estão mais concentradas nas regiões Sul e Sudeste. Cláusulas que tratam da questão da prevenção,

\footnotetext{
${ }^{1}$ Recebido em 12/04/2018, aprovado em 20/10/2018.

${ }^{2}$ Universidade do Estado de Minas Gerais; Belo Horizonte - MG (Brasil) - rafaelmaianogueira@gmail.com

3 Pontifícia Universidade Católica de Minas Gerais - Programa de Pós-Graduação em Administração; Belo Horizonte - MG (Brasil) - carvalhoneto@pucminas.br

4 Centro Universitário UNA - Mestrado Profissional em Administração; Belo Horizonte - MG (Brasil) adm.thiagosn@gmail.com
} 
prescrevendo programas, palestras e outros, bem como a associação com o assédio sexual, foram as que tiveram maior frequência. Por outro lado, aquelas associadas a participação sindical e apoio a vítimas.

Palavras-Chave: Sindicalismo. Assédio Moral. Relações de Trabalho. Acordos e convenções coletivas de trabalho.

THE WORKPLACE BULLYING IN COLLECTIVE BARGAINING AND COLLECTIVE AGREEMENTS: ANY LIGHT AT THE END OF THE TUNNEL?

\begin{abstract}
The union action in relation to workplace bullying, although timid, has intensified over the last decades due to the degradation of the working conditions and sickness of the worker, pressured by the current economic and social system of competitiveness. The article aimed to investigate how workplace bullying has been placed within constant collective bargaining and collective agreements. It is qualitative and descriptive research. The data used in the survey were collected in the database of the Department of Statistics and Socioeconomic Studies (DIEESE), which consists of 177 specific clauses that deal with moral harassment in the period between 2011 and 2016. For data analysis, the content analysis, according to 7 categories of analysis. The number of clauses is relatively small if one considers the universe of unions affiliated to the Department, but a small evolution in the quantity of clauses in the period, which are more concentrated in the South and Southeast regions, can be observed. Clauses dealing with the issue of prevention, prescribing programs, lectures and other, as well as the association with sexual harassment, were those that had more frequency. On the other hand, those associated with union participation and support for victims.
\end{abstract}

Keywords: Syndicalism. Workplace bullying. Work relationships. collective bargaining and collective agreements.

\title{
EL ACOSO LABORAL EN LOS ACUERDOS Y CONVENIOS COLECTIVAS DEL TRABAJO: ¿alguna luz al final del túnel?
}

\section{RESUMEN}

REAd | Porto Alegre - Vol. 24 - No 3 - Setembro / Dezembro 2018 - p. 21-45 
La actuación sindical en relación al acoso laboral, aunque tímida, se ha intensificado a lo largo de las últimas décadas derivadas de la degradación de las condiciones laborales y de la enfermedad del trabajador, presionado por el actual sistema económico y social de competitividad. El artículo objetivó investigar cómo el acoso laboral ha sido colocado dentro de los acuerdos y convenciones colectivas de trabajo constantes. Se trata de una investigación cualitativa y descriptiva. Los datos utilizados en la investigación fueron recolectados en el banco de datos del Departamento Intersindical de Estadística y Estudios Socioeconómicos (DIEESE), que consisten en 177 cláusulas específicas que versan sobre acoso laboral en el período comprendido entre 2011 y 2016. Para el análisis de datos, análisis de contenido, de acuerdo con 7 categorías de análisis. El cuantitativo de cláusulas es relativamente pequeño si se considera el universo de entidades sindicales afiliadas al Departamento, pero se puede observar una pequeña evolución en el cuantitativo de cláusulas en el período, que están más concentradas en las regiones Sur y Sudeste. Las cláusulas que tratan la cuestión de la prevención, prescribiendo programas, conferencias y otros, así como la asociación con el acoso sexual, fueron las que tuvieron mayor frecuencia. Por otro lado, aquellas asociadas a la participación sindical y apoyo a las víctimas.

Palabras clave: Sindicalismo. Acoso laboral. Relaciones de trabajo. Acuerdos y convenios colectivas de trabajo.

\section{INTRODUÇÃO}

As alterações significativas na economia e na sociedade culminaram na crise do modelo fordista de produção, turbinada pelo advento das novas tecnologias da informação, com uma diminuição conceitual gradativa da importância do mundo do trabalho frente a fatores externos, de tal sorte que os sindicatos passaram a apresentar novas demandas dos trabalhadores que fogem ao escopo tradicional (OFFE, 1989; CASTELLS, 1999; PIORE, 2011). O assédio no trabalho, que consiste em uma modalidade de agressão psicológica com consideráveis danos para a vítima, torna-se objeto de interesse dos gestores a partir da visualização dos efeitos negativos que tal violência pode proporcionar para a empresa (FREITAS, 2001; NUNES; TOLFO, 2012a).

Nesse sentido, este trabalho investigou como o assédio moral tem sido tratado dentro dos acordos e convenções coletivas de trabalho. Por meio de análise documental, levantou-se 
o número de acordos que abrangem também o assédio sexual, e os que preconizam o estabelecimento de Comissão ou Conselho para tratar do Assédio Moral no Trabalho, bem como participam desses órgãos; sendo quantos estabelecem expressamente a punição ao agressor, apuração de casos e apoio às vítimas; quantos estabelecem programas, capacitações e outros meios de prevenção para prevenção do assédio no trabalho.

O trabalho ora apresentado revela-se como uma importante contribuição ao cenário acadêmico uma vez que, não se identificou muitas publicações visando analisar a atuação sindical frente ao assédio no trabalho, na amplitude ora apresentada, embora haja um número significativo de trabalhos sobre o tema (EMMENDOERFER; TOLFO; NUNES, 2015). A análise dessas cláusulas revela como tem sido a atuação sindical frente ao assédio moral. De tal sorte, este estudo poderá vir a servir como um subsídio para outros sindicatos e empresas aprimorem sua atuação prevenção e coibição desse tipo de violência.

A partir do exposto, o artigo encontra-se estruturado de modo a apresentar uma breve abordagem sobre a crise do modelo dunlopiano de relações de trabalho e o sindicalismo no Brasil e o assédio moral no trabalho, além da descrição do método adotado nesta pesquisa, a discussão e análise dos resultados. Por fim, são apresentadas as considerações sobre os principais aspectos identificados nesta pesquisa.

\section{A CRISE dO MOdelo DUNLOPIANO DE RELAÇÕES DE TRABALHO E O SINDICALISMO NO BRASIL}

O modelo dunlopiano de Sistemas de Relações de Trabalho os explica por meio da existência de um pacto entre os três grandes atores sociais coletivos, caracterizados pelos representantes da classe trabalhadora, representantes dos empregadores e do governo, os quais negociam contratos reguladores do trabalho (DUNLOP, 1993). Assim, por meio de um ajuste do interesse das partes, estabelece-se um conjunto de regras que intervêm nas condições de trabalho, condicionado a certos contextos e ideologias (SARAIVA; FERREIRA; COIMBRA, 2012).

Trata-se de um modelo que, por um lado, aceita o papel de representação coletiva de interesses desempenhado pelos sindicatos de trabalhadores, bem como suas formas de manifestação como a greve, e por outro, aceita o sistema capitalista de produção, na medida em que reconhece a possibilidade de acordo entre as classes trabalhadora e empregadora (DUNLOP, 1993). Obviamente, como já salientava Dunlop (1993) o poder de cada ator social em determinada sociedade leva a maiores ou menores concessões de lado a lado. Nesta

REAd | Porto Alegre - Vol. 24 - No 3 - Setembro / Dezembro 2018 - p. 21-45 
linha, Saraiva, Ferreira e Coimbra (2012) asseveram que, em geral, os acordos firmados entre os atores sociais no Brasil são mais influenciados pelos interesses dos empregadores, mesmo nos casos em que os trabalhadores conseguem impor parte de suas demandas, tendo em vista a assimetria de força entre esses atores dentro do sistema capitalista brasileiro.

Esse modelo se funda na ideia de um tipo de trabalho, chamada comumente de trabalho padrão ou convencional, regido por um contrato padrão por prazo indeterminado, realizado nas dependências da empresa e sob a supervisão do empregador, em que o empregado possui remuneração e horários fixos (AZEVEDO; TONELLI; SILVA, 2015). Tem-se algumas premissas fundamentais no modelo dunlopiano, sendo a primeira a existência de uma ideologia comum entre os elementos que compõem cada ator social, que compreende o seu papel dentro das relações de trabalho e compreende o papel dos outros dentro da arena negocial, sendo esta fonte de estabilização e controle do sistema (DUNLOP, 1993).

Todavia, a partir da década de 1970, novas formas de contratações mais precárias, diferentes das observadas no período fordista, começam a surgir, como é o caso da terceirização, subcontratação, círculo de controle de qualidade total, kanban, just in time, kaizen, team work, eliminação do desperdício, "gerência participativa" e sindicalismo de empresa (ANTUNES; DRUCK, 2015), chegando ao processo de uberização, colocado por Bombonati (2017) como o atual apogeu da flexibilização e perda de direitos.

Assim, surgiu a teoria da escolha estratégica, cuja importante referência é Kochan, que reconhece que o sistema de relações de trabalho surge naturalmente de uma combinação entre o que é inerente, o que é conflituoso e os interesses comuns, sendo regulado pelo poder, pelas escolhas estratégicas e pelas habilidades de negociação que cada um dos atores sociais coletivos traz para suas interações (TAPIA; IBSEN; KOCHAN, 2015). Nesse sentido, os sistemas de relações de trabalho derivam da interação de três elementos, quais sejam as escolhas estratégicas feitas pelos atores sociais, às estruturas da negociação coletiva e a divisão técnica do trabalho, de modo que a primeira é a que mais influi nos processos de mudança, e as negociações coletivas, por si, passariam a compor um nível secundário na análise (CARVALHO NETO, 2001).

A teoria desenvolvida por Kochan, Katz e McKersie, contrastou os padrões de modelo de relações de trabalho do período fordista, em que prevaleciam práticas e procedimentos de controle de trabalhadores, postos de trabalho fixos e salários fixos, com os novos padrões de relações de trabalho, mais participativos, centrados no trabalho em equipe e em salários variáveis. Foram identificados, nesse novo modelo, a emergência de sofisticados padrões não 
aderentes à política sindical, tornando-se um grande desafio para a as práticas sindicais tradicionais (KATZ, 2013).

Estes fatores levaram à crise do sindicalismo, consenso na literatura, o que pode ser evidenciado observando-se a queda nas taxas de sindicalização, que atualmente estão significativamente baixas, e de movimentos grevistas (GUIMARÃES; CARVALHO NETO, 2006; PORTO; CARVALHO NETO, 2011). Por um lado, esse novo contexto do mercado de trabalho levou a uma heterogeneidade da força de trabalho representada pelos sindicatos, com vínculos e jornadas de trabalho diferentes, e por outro lado, a falta de identidade atual que os trabalhadores possuem com o movimento sindical, consequência de uma não identificação coletiva que provoca o individualismo na classe trabalhadora (PORTO; CARVALHO NETO, 2011). Observa-se uma fragilidade das entidades de representação dos trabalhadores, que tem como fonte diversos motivos, como a politização das centrais sindicais e a falta de capacidade em ultrapassar a tradicional discussão referente a remuneração (CRUZ; SARSUR; AMORIM, 2012). Dessa forma, Cruz, Sarsur e Amorim (2012) asseveram que a valorização do conhecimento e estimulo à carreira individualizada consiste em um contraponto ao trabalho coletivo, questionando, assim, o papel dos sindicatos nesse contexto. Nesse sentido, os sindicatos deveriam buscar novas estratégias que, somadas às suas atividades tradicionais, permitam uma ampliação do seu espectro de atuação e auxiliem no enfrentamento aos obstáculos que se apresentam (GUIMARÃES; CARVALHO NETO, 2006).

Na perspectiva brasileira, a facilitação do processo de criação de sindicatos sempre foi enorme, dado que são divididos, fragmentadíssimos legalmente por base geográfica e categoria profissional, o que ampliou em muito o número de sindicatos e de novas categorias profissionais (CARVALHO NETO; AMORIM; FISCHER, 2016). O número total de sindicatos pulou de cerca de 2.000 em 1964 para o quantitativo atual de 11.240 sindicatos, um aumento de mais de 400\% no período (CARDOSO, 2015; CAMPOS, 2016). Essa ampliação não guarda relação com o crescimento da base sindical, que se encontra no menor patamar dos últimos dezessete anos. Nesse sentido, o crescimento do número de sindicatos não resultou em uma ampliação da sustentação das bases, tampouco no fortalecimento do poder de barganha, podendo ser explicado, talvez, também pelo interesse dos líderes sindicais em pegar uma "fatia do bolo" do imposto sindical, que não depende da luta sindical para ser arrecadado (CARVALHO NETO; AMORIM; FISCHER, 2016).

De acordo com Carvalho Neto, Amorim e Fischer (2016), a partir da ascensão do Partido dos Trabalhadores ao poder no ano de 2003, bem como da retomada do crescimento 
econômico, as manifestações por melhores condições de trabalho voltaram para a agenda das negociações coletivas. Esse revigoramento do sindicalismo abrangeu tanto áreas tradicionalmente fortes, como bancos e indústria automobilística, quanto em outras com histórico de baixa atuação sindical, chegando a mobilizar até mesmo trabalhadores não sindicalizados.

Desde a sua origem, os sindicatos brasileiros são estruturados em um sistema em que o enquadramento é por categoria profissional, de acordo com uma base territorial definida, possuindo uma estruturação verticalizada, podendo ser compostas por federações sindicais, que compreendem um coletivo de cinco ou mais sindicatos, e confederações sindicais, que é o coletivo de três ou mais federações (COSTA, 2005). Somente em 2008, no segundo mandato do Presidente Lula, as Centrais Sindicais, que compreendem sindicatos entre diferentes categorias, como a Central Única dos Trabalhadores (CUT) e a Força Sindical, foram reconhecidas por lei e passaram a receber um percentual do imposto sindical (CARVALHO NETO; AMORIM; FISCHER, 2016).

Não se observa, nesse período, um crescimento na taxa de filliação sindical, que ampliou de 19,3\% em 2001 para 21\% em 2006, ficando praticamente estável, ainda que seja um feito positivo considerando o contexto internacional, andando na contramão da tendência mundial de enfraquecimento dos sindicatos. Todavia, a partir de então se observou um declínio acentuado do poder de pressão do sindicalismo no Brasil, seja pelas estatísticas de greves publicadas pelo Departamento Intersindical de Estatística e Estudos Socioeconômicos (DIEESE), seja pela taxa de $16,2 \%$ de filiados a sindicatos, que caiu quase cinco pontos percentuais entre 2006 e 2017, chegando a ter queda nominal de filiados entre 2012 e 2013 (CARDOSO, 2015; CAMPOS, 2016). Nesse mesmo sentido, pesquisas recentes realizadas junto às áreas de gestão de pessoas apontaram a existência de altas taxas de trabalhadores temporários, bem como a fraca influência dos sindicatos nas decisões das empresas (CARVALHO NETO; AMORIM; FISCHER, 2016).

Esse contexto de crise se agrava a partir de 2017, quando são aprovadas a Lei $\mathrm{n}^{\circ}$ 13.467 e a Lei ${ }^{\circ}$ 13.429, que, de acordo com Krein (2018) e com DIEESE (2017a), trouxe mudanças estruturais que impactaram diretamente no papel dos sindicatos nas relações de trabalho, como: a prevalência do negociado em detrimento do legislado; prevalência dos acordos sobre as convenções coletivas de trabalho; fim da ultratividade das negociações, limitando a vigência das contratualizações coletivas a dois anos; possibilidade da negociação individual em detrimento da coletiva; a supervisão das homologações dos trabalhadores pelos 
sindicatos,; sendo que o primeiro autor acrescenta o estrangulamento financeiro das entidades sindicais com o fim do imposto sindical.

Nesse mesmo sentido, o DIEESE (2017c) assevera que a reforma trabalhista piora significativamente os sistemas de contrato, jornada e remuneração de trabalho, na medida em que regulamenta novas formas precárias de trabalhos, como o intermitente, amplia trabalhos atípicos, como o parcial, e amplia consideravelmente a terceirização, consiste em um verdadeiro retrocesso na medida em que reduz drasticamente os direitos trabalhistas. Trata-se de um movimento feroz de desmantelamento do sistema protetivo brasileiro que altera

[...] os direitos trabalhistas individuais e o direito de garanti-los, as condições de exercício do trabalho (jornada, ambiente, uniforme, equipamentos), as formas de contratação e de demissão, as formas de remuneração, o processo da negociação coletiva, inclusive quanto ao papel da Justiça do Trabalho, os instrumentos de ação sindical, o financiamento da organização sindical e a estrutura sindical (DIEESE, 2017b, p. 16).

O fato é que o sindicalismo brasileiro está em crise, assim como acontece em outros países, e pode-se discorrer algumas causas desse cenário. Todavia, novas formas de atuação, que extrapolam àquelas tradicionalmente praticadas pelo sindicalismo brasileiro, começam a ser observadas em âmbito nacional com extrapolações internacionais, como no caso da formação de redes de sindicatos de empresas multinacionais, com o apoio das confederações e centrais sindicais, que consistem na articulação e organização de trabalhadores de diferentes unidades de uma mesma empresa, em âmbito nacional e internacional, com vistas a construir uma agenda comum de negociação (COSTA, 2016).

Apesar da crise estruturante no sindicalismo brasileiro, a atuação sindical precisa cada vez mais ser intensificada para assegurar a qualidade de vida, saúde e segurança no trabalho frente à constante crise financeira, laboral e ética que vivenciamos. Portanto, na próxima seção desenvolve-se sobre o tema assédio moral no trabalho, suas características e o vínculo deste tema com a atuação sindical.

\section{ASSÉDIO MORAL NO TRABALHO}

A partir dos anos 1990, a pauta do assédio moral no trabalho entrou de vez como objeto de estudo e interesse por parte dos pesquisadores da área da Administração. De acordo com Freitas (2001), é neste momento que ele passou a ser visto como destrutivo do ambiente de trabalho, haja vista a queda de produtividade e o absenteísmo provocado pelos danos psicológicos. Para Nunes e Tolfo (2012a), a partir da visualização dos efeitos negativos que a

REAd | Porto Alegre - Vol. 24 - No 3 - Setembro / Dezembro 2018 - p. 21-45 
violência pode proporcionar para a organização, é que os gestores deram maior atenção para estes aspectos.

Decerto, a humilhação dentro do trabalho é algo que existe desde sempre, aparecendo de diferentes maneiras conforme o contexto (HELOANI, 2004). Todavia, vários pesquisadores entendem que, com a crise do Fordismo e o consequente advento de regimes econômicos de orientação mais fortemente neoliberais, com políticas antagônicas que exigem do trabalhador cooperação com acirramento da competição, ocorreu uma intensificação do desgaste físico e mental dos trabalhadores, o que ampliou o número de casos de condutas abusivas e de assédio (HELOANI, 2004; SCANFONE; TEODÓSIO, 2004. ARAÚJO, 2017).

De acordo com Heloani (2004), no passado o assédio ocorria basicamente com os profissionais da base hierárquica, tendo ocorrido um processo de "democratização" que alcançou profissionais bastante qualificados, como professores universitários, médicos e juízes. Ou seja, o assédio moral não é um privilégio de organizações públicas ou privadas, de países mais ou menos desenvolvidos, é uma situação que ocorre em qualquer ambiente laboral (HELOANI; BARRETO, 2018).

Muitos estudos apontam que, para boa parte dos empregados, o assédio moral é um aspecto nocivo e persistente na vida organizacional (HARRINGTON; WARREN; RAYNER, 2015). Nessa linha, Freitas (2007) e Nunes e Tolfo (2013a) salientam que o assédio moral é uma questão organizacional na medida em que permite a ocorrência desse tipo de violência quando não estipulam limites em regras ou instâncias de punição, apesar de não ser algo deliberado de seus dirigentes. Em contrapartida, no atual cenário de negócios dominado por busca de alta competitividade e a busca contínua e incessante por aumentos exponenciais de produtividade, muitos gestores adotam como princípio norteador o resultado e o lucro a qualquer custo, o que possibilita que excessos sejam cometidos para "fugir da crise" (TOLFO; SILVA; KRAWULSKI, 2013). Ou seja, o assédio moral pode ser visto como parte da cultura, de modo que a sua prática é permitida, veladamente, como uma estratégia para alcançar metas ambiciosas e desempenho almejado (SALIN, 2013; NUNES; TOLFO, 2013a).

A caracterização de uma situação como assédio moral é um trabalho complexo, que denota atenção. Para Einarsen et al. (2005; 2011) e Nunes e Tolfo (2015), há um conjunto de características que definem o assédio moral no trabalho, quais sejam: a prática pode ser intencional ou não, de modo que a não intencionalidade do ato não o torna menos violento ou danoso à vítima; a direcionalidade, que é a um indivíduo ou a um grupo específico; a frequência, de modo que o assédio moral é ato frequente e repetitivo que ocorre mais 
habitualmente durante meses e anos; o desequilíbrio de poder, situações em que a capacidade de ataque e defesa de cada um é desigual, não remetendo necessariamente a poder hierárquico; e o caráter processual, haja vista que o assédio moral evolui gradativamente, passando de situações mais escamoteadas para ataques mais visíveis e violentos.

O assédio moral pode ser compreendido como:

[...] conduta abusiva, intencional, frequente e repetitiva, que ocorre no meio ambiente laboral, cujo causalidade se relaciona com as formas de organizar o trabalho e a cultura organizacional, que visa humilhar e desqualificar um indivíduo ou um grupo, degradando as suas condições de trabalho, atingindo a sua dignidade e colocando em risco a sua integridade pessoal e profissional (HELOANI; BARRETO, 2018, p. 53).

$\mathrm{O}$ assédio moral pode ter diversas origens quanto à posição hierárquica dos agressores em relação ao agredido (NUNES; TOLFO, 2015). Conforme Gonçalves (2009), o assédio moral pode ser classificado como assédio moral vertical, horizontal, misto, específico, genérico ou social. De acordo com o autor, o assédio moral vertical pode ser ascendente ou descendente, sendo o primeiro praticado pelo hierarquicamente inferior ao superior e o segundo o contrário; horizontal, quando os envolvidos são pessoas em um mesmo plano hierárquico; o misto consiste no encontro entre o horizontal e o vertical; o assédio moral específico é aquele que tem um espaço definido para ocorrer; e o assédio moral genérico ou social ocorre de modo aberto, geralmente em espaços públicos. Há também o assédio moral grupal, que é aquele relacionado à identidade de grupo que os empregados levam para dentro da organização, bem como os conflitos existentes na sociedade em geral, podendo acarretar em comportamentos de assédio moral, como ridicularizações, destratamentos e isolamentos (SOYLU; SHEEHY-SKEFFINGTON, 2015). Nesse sentido, as pessoas pertencentes a grupos historicamente discriminados, como é o caso das mulheres, dos negros, das pessoas com deficiências e dos homossexuais, estariam mais suscetíveis a sofrer o assédio moral no ambiente de trabalho (HIRIGOYEN, 2006).

As situações de assédio moral podem ser classificadas de modo progressivo em relação com sua visibilidade, como: deterioração proposital das condições de trabalho, em que são praticados atos para que o alvo pareça ser incompetente, em geral proveniente de superiores; isolamento e recusa de comunicação, em que ocorrem ações de recusa da comunicação e de exclusão dos eventos sociais, ocorrendo tanto por superiores quanto por pares; atentado contra a dignidade, em que são desferidos atos de desprezo, de desqualificação ou chacotas, geralmente desferidas por pares; e violência verbal, física ou sexual, em que os atos de violência se apresentam como ameaças, violência física e assédio 
sexual, podendo extrapolar o ambiente de trabalho (HIRIGOYEN 2006; NUNES; TOLFO, 2015).

No que diz respeito ao combate do assédio moral, as organizações devem reconhecer a possibilidade de ocorrência do fato e atuar positivamente nas atividades de apurar, coibir, punir os responsáveis, sem exceções (FREITAS, 2007; NUNES; TOLFO, 2012b). O empregador deve zelar por um trabalho saudável, sendo o assédio moral uma clara violação ao contrato de relação de trabalho (VASCONCELOS, 2015). Todavia, ao analisar as denúncias de assédio moral de acordo com a perspectiva dos profissionais de recursos humanos, Harrington, Warren e Rayner (2015) detectaram dificuldades desse grupo em decidir entre a palavra do acusador e do acusado, bem como uma pressão da gestão por resolução rápida do conflito minimizando danos à organização.

É nessa lacuna de atuação que os sindicatos, representantes dos interesses dos trabalhadores, deveriam marcar presença, reivindicando uma atuação mais forte das organizações de modo a garantir que esta forma de violência seja extirpada do ambiente de trabalho. Para Barreto (2006) e Bradaschia (2007), a atuação dos sindicatos em questões referentes ao assédio moral ainda é muito tímida. No entanto, existem alguns que se destacam, como o sindicato dos bancários, que possui uma atuação relevante no cenário nacional. Fabro e Maehler (2015) relatam que o enfraquecimento das lideranças nas organizações sindicais possibilita que o assédio moral, que deveria ser tratado enquanto uma ação coletiva, seja discutido numa perspectiva individualizada e de forma sigilosa na esfera psicológica.

Portanto, cabe aos sindicatos colocarem como pauta nas discussões coletivas a saúde e a segurança do trabalhador como um aspecto primordial. Desta forma, podem combater diversas mazelas, entre elas o assédio moral, por meio da inserção de cláusulas que coíbam esta e outras práticas vexatórias e humilhantes aos quais os trabalhadores são submetidos (LUNA, 2003; FABRO; MAEHLER, 2015). Ademais, as organizações sindicais necessitam oferecer um suporte e apoio ao indivíduo que denuncia a violência, oferecendo assessoria e orientação, e reportando o andamento do processo - o qual deve ser acompanhado por um representante sindical para garantir a imparcialidade do mesmo (LUNA, 2003).

Em um levantamento realizado por Fabro e Maehler (2015) sobre práticas adotadas pelas organizações sindicais do estado de Santa Catarina em relação ao assédio moral, foi identificado alguns aspectos: a) pouca informação e de baixa qualidade sobre o assédio moral nos sites dos sindicatos (conceitos, situações e características); b) razoável divulgação de notícias sobre casos de assédio moral, principalmente de outros estados; c) nenhuma 
informação nos sites, de instruções de como proceder para denunciar o assédio moral; d) aumento de cláusulas sobre assédio moral nos acordos coletivos. Nunes e Tolfo (2012b) acreditam que a informação é uma importante ferramenta para a prevenção e combate ao assédio moral, assim, cabe aos sindicatos desenvolverem ações de orientação e informação sobre a violência no âmbito virtual e nas suas dependências. Cabe ressaltar, que no primeiro momento, as vítimas podem se sentir constrangidas e com medo de denunciar (NUNES; TOLFO, 2013b), portanto, desenvolver estas informações nos sites, servirá como uma primeira etapa para elas terem uma orientação do que estão passando no momento e de como proceder futuramente.

Por fim, cabe ressaltar a importância da atuação sindical para com o trabalhador assediado, que muitas vezes se encontra fragilizado e desamparado, e em busca de um apoio e orientação para cessar com as situações vivenciadas no ambiente laboral. Logo, a sua atuação deve sempre buscar ou ter como foco a saúde e segurança do trabalhador.

\section{METODOLOGIA}

A abordagem da pesquisa desenvolvida foi qualitativa e o estudo tem caráter descritivo, tendo em vista que se trata de um estudo empírico pouco tratado na literatura quando se considera a atuação sindical contra o assédio moral por meio de contratos e convenções coletivas de trabalho. O caráter descritivo da pesquisa, no caso em questão, coaduna com o objetivo de investigar como o assédio moral tem sido tratado dentro dos acordos e convenções coletivas de trabalho. O método adotado para o presente estudo foi a análise documental, pois se trata da análise de documentos, quais sejam as cláusulas de acordos e convenções coletivas de trabalho, que ainda não receberam analítico, tendo em vista os objetivos supramencionados. De acordo com Yin (2005), a tal tipo de análise tem como pontos fortes o fato de ser estável e de ampla cobertura.

Foi realizada uma análise das cláusulas presentes nos acordos e nas convenções coletivas de trabalho celebrados entre sindicatos de trabalhadores e empregadores em todo o Brasil que tenham relação com o objeto assédio moral. Os dados foram coletados por meio de contato junto ao Departamento Intersindical de Estatística e Estudos Socioeconômicos DIEESE, departamento ligado a entidades sindicais que possui como objetivo desenvolver pesquisas que subsidiassem as demandas dos trabalhadores e, atualmente, mantem em seu corpo filiado mais de 700 sindicatos, federações e confederações nacionais de trabalhadores. Foram fornecidas todas as cláusulas específicas que versam sobre o assédio moral no período 
compreendido entre 2011 e 2016. Para tanto, foram analisados um total de 5.503 cláusulas de acordos e convenções coletivas entre 209 categorias de trabalhadores e respectivos empregadores. É importante ressaltar que o DIEESE acompanha a realização das convenções coletivas e as tabulam em banco de dados específico presente no Sistema de Acompanhamento das Contratações Coletivas.

A estratégia de análise dos dados das cláusulas foi a análise de conteúdo, que consiste em uma técnica de análise de textos objetivada para produção de inferências, a partir da frequência da ocorrência de categorias delineadas (BAUER, 2003). Para tanto, foram verificadas, tanto dentro das cláusulas de acordos e convenções coletivas categorias constituídas por meio do referencial teórico combinado com o problema deste trabalho que qualifiquem esta atuação entre os anos de 2010 e 2017. Destaca-se que as cláusulas iniciadas antes de 2010 e finalizadas em 2011 não foram contabilizadas, o que diminui o quantitativo desse ano. Em 2016, não foram contabilizadas as cláusulas iniciadas e finalizadas neste ano, haja vista que não há, nos documentos encaminhados pelo DIEESE, dados relativos a 2016. Por fim, com relação às marcações relativas a 2017, elas se referem a cláusulas cuja vigência iniciou em 2015 e finalizou em 2017. Portanto, para observar crescimento ou não, o intervalo entre 2012 e 2015 é o ideal, mas serão analisados os dados de 2011 até 2016.

O trabalho consiste em um recorte de estudo realizado nas cláusulas do DIEESE que analisou 5.503 cláusulas relacionadas a mulheres, negros, pessoas com relação homoafetiva, pessoas com deficiências e contra os assédios moral e sexual. Deste modo, foram acrescidas cláusulas que inicialmente não estavam relacionadas com o assédio moral nos filtros do Departamento, mas que tratam do tema, como no caso das cláusulas firmadas entre a Celesc Distribuição S/A e os sete sindicatos que representam seus funcionários, vigentes entre 2011 e 2015, conforme abaixo:

\section{ORIENTAÇÃO QUANTO A COIBIÇÃO DE PRÁTICAS DISCRIMINATÓRIAS}

Denúncias de assédio moral, sexual e outras formas de discriminação de sexo, raça, religião ou ideologia, serão encaminhadas à Diretoria de Gestão Corporativa, com conhecimento da INTERCEL para abertura de procedimentos investigatórios junto ao comitê de ética, que e, 30 dias emitirá relatório conclusivo dos fatos e; se houver responsável(is), esse(s) responderá(ão) conforme dispõe as normativas internas e leis vigentes. Parágrafo único: A Celesc Distribuição desenvolverá campanhas de conscientização e orientação destinadas a prevenir a ocorrência de tais distorções e coibir atos e posturas discriminatórias nos ambientes de trabalho, tendo como principal objetivo proteger de todas as formas o empregado vitimado.

As categorias de análise verificadas foram: tratar especificamente do assédio sexual; evolução do quantitativo de cláusulas por ano; quantitativo de cláusulas genéricas, que não REAd | Porto Alegre - Vol. 24 - No 3 - Setembro / Dezembro 2018 - p. 21-45 
especificam nenhuma das categorias a seguir; cláusulas que abrangem também o assédio sexual, cláusulas que preconizam o estabelecimento de Comissão ou Conselho para tratar do Assédio Moral no Trabalho; dentre as cláusulas da categoria anterior, aquelas que estabelecem participação sindical na Comissão ou Conselho; estabelecimento expresso de punição ao agressor; estabelecimento de programas, capacitações e outros meios de prevenção; previsão de apoio às vítimas; e participação sindical na apuração e punição dos casos de assédio.

Esses dados coletados foram tabulados em bancos de dados específicos de acordo com a categoria de modo a possibilitar interpretações e realizar inferências sobre o fenômeno analisado.

\section{ANÁLISE DOS RESULTADOS}

Primeiramente, levantou-se o quantitativo de dispositivos que abrangiam a temática do assédio moral no trabalho. A Tabela 1 demonstra a evolução do número de cláusulas no período entre 2011 e 2017.

Tabela 1- Cláusulas de assédio moral - 2011 a 2017

\begin{tabular}{lccccccc}
\hline HIPÓTESE/ANO & 2011 & 2012 & 2013 & 2014 & 2015 & 2016 & 2017 \\
\hline Cláusulas vigentes & 22 & 32 & 38 & 37 & 32 & 16 & 1 \\
\hline
\end{tabular}

Fonte: dados primários (2017).

Observa-se um total de 177 neste período, todavia 27 cláusulas foram contadas duas vezes, pois os acordos e convenções coletivas de trabalho tiveram vigência por dois anos consecutivos dentre os observados, contemplando 43 categorias profissionais. Houve um crescimento do quantitativo de cláusulas entre 2011 e 2013, com uma pequena redução em 2014 e 2015.

Esse quantitativo de cláusulas, em comparação com outras temáticas como mulheres, que possui mais de 4 mil cláusulas no período e 200 categorias profissionais, é bem pequeno, o que demonstra um relativo desinteresse das entidades sindicais em consolidar, nos Acordos e Convenções Coletivas de Trabalho cláusulas que se destinem à prevenção e punição de práticas de assédio moral. Mesmo nesse quantitativo, identificou-se que haviam cláusulas com caráter genérico, compreendidas como aquelas que preveem o combate ao assédio moral, todavia não especificam o modo de combate: em 2011 foram identificados 2 cláusulas, 4 em 2012, 9 em 2013, 8 em 2014, 7 em 2015 e 3 em 2016. Nesse sentido, foram levantados 
dispositivos como o do sindicato dos Metalúrgicos de Jaraguá do Sul, em Santa Catarina, que assim dispõe "As partes envidarão esforços no sentido de prevenir a prática de assédio moral nas relações de trabalho", que destacam a importância de se combater o assédio moral, todavia não agregam diretrizes concretas de como coibir e evitar essa violência. Para Einarsen e Hoel (2008) e Nunes e Tolfo (2012b) as medidas de prevenção e combate ao assédio devem estar explícitas, e principalmente, sair do discurso e ir para a prática. Pois, segundo os autores, somente com a prática de combate ao assédio moral os trabalhadores darão credibilidade as intenções organizacionais.

Acerca da distribuição regional dos sindicatos, identificou-se entidades cuja abrangência territorial é nacional, estadual e municipal, abrangendo os estados de São Paulo, Minas Gerais, Rio de Janeiro, Bahia, Distrito Federal, Ceará, Paraná, Santa Catarina, Pará, Pernambuco, Rio Grande do Norte e Rio Grande do Sul. A Tabela 2 demonstra essa evolução.

Tabela 2- Distribuição regional dos sindicatos - 2011 a 2017

\begin{tabular}{|c|c|c|c|c|c|c|c|c|}
\hline REGIÃO & 2011 & 2012 & 2013 & 2014 & 2015 & 2016 & 2017 & UF \\
\hline Norte & 2 & 2 & 2 & 2 & 2 & 2 & 0 & Pará \\
\hline Nordeste & 8 & 8 & 8 & 8 & 5 & 1 & 0 & $\begin{array}{l}\text { Ceará, Rio Grande do Norte, } \\
\text { Bahia e Pernambuco }\end{array}$ \\
\hline $\begin{array}{l}\text { Centro- } \\
\text { oeste }\end{array}$ & 1 & 1 & 1 & 1 & 1 & 1 & 0 & Distrito Federal \\
\hline Sudeste & 4 & 6 & 9 & 9 & 10 & 5 & 1 & $\begin{array}{l}\text { Minas Gerais, São Paulo } \\
\text { e Rio de Janeiro }\end{array}$ \\
\hline Sul & 4 & 9 & 10 & 10 & 7 & 3 & 0 & $\begin{array}{l}\text { Paraná, Santa Catarina } \\
\text { e Rio Grande do Sul }\end{array}$ \\
\hline Nacional & 3 & 6 & 8 & 7 & 7 & 4 & 0 & \\
\hline
\end{tabular}

Fonte: Dados primários (2017).

Destaca-se a participação dos estados do nordeste e sul no quantitativo geral, especialmente do estado do Rio Grande do Sul, que tem quase o mesmo quantitativo de cláusulas de São Paulo, que é o estado e a região onde os sindicatos tradicionalmente são mais atuantes. Destaca-se que alguns sindicatos marcados como de abrangência nacional, como a confederação que representa os bancários, possui sua sede no estado de São Paulo.

Com relação aos setores dos sindicatos, têm-se abrangidos os trabalhadores dos setores bancário, comercial, correios, eletricitário, extrativista, gráfico, jornalista, metalúrgico, petroquímico, plástico, processamento de dados, purificação e tratamento de 
água, químico, rural, saúde, telefonia, telecomunicação, telemarketing, têxtil, transporte e vidreiro, conforme a Tabela 3.

Tabela 3- Cláusulas por setor - 2011 a 2017

\begin{tabular}{lccccccc}
\hline \multicolumn{1}{c}{ CLÁUSULAS POR SETOR } & $\mathbf{2 0 1 1}$ & $\mathbf{2 0 1 2}$ & $\mathbf{2 0 1 3}$ & $\mathbf{2 0 1 4}$ & $\mathbf{2 0 1 5}$ & $\mathbf{2 0 1 6}$ & $\mathbf{2 0 1 7}$ \\
\hline Bancário & 1 & 1 & 3 & 1 & 1 & 0 & 0 \\
Comércio & 3 & 3 & 3 & 3 & 2 & 2 & 0 \\
Correios & 0 & 1 & 1 & 1 & 1 & 1 & 0 \\
Eletricitário & 3 & 4 & 5 & 5 & 5 & 0 & 0 \\
Extrativista & 0 & 0 & 0 & 1 & 1 & 0 & 0 \\
Gráfico & 0 & 0 & 0 & 0 & 1 & 0 & 0 \\
Jornalista & 3 & 3 & 3 & 3 & 2 & 1 & 0 \\
Metalúrgico & 0 & 3 & 3 & 3 & 2 & 1 & 1 \\
Petroquímico & 0 & 1 & 1 & 0 & 0 & 0 & 0 \\
Plástico & 2 & 2 & 2 & 2 & 2 & 2 & 0 \\
Processamento de dados & 1 & 3 & 3 & 3 & 3 & 3 & 0 \\
Purificação e distribuição de água & 3 & 3 & 3 & 3 & 2 & 1 & 0 \\
Químico & 1 & 2 & 2 & 2 & 2 & 1 & 0 \\
Rural & 2 & 2 & 2 & 2 & 1 & 0 & 0 \\
Saúde & 0 & 1 & 1 & 1 & 1 & 0 & 0 \\
Telefonia & 0 & 0 & 2 & 2 & 1 & 0 & 0 \\
Telecomunicação & 0 & 0 & 1 & 1 & 1 & 1 & 0 \\
Telemarketing & 1 & 1 & 1 & 2 & 1 & 1 & 0 \\
Têxtil & 1 & 1 & 1 & 1 & 1 & 0 & 0 \\
Transporte & 1 & 1 & 1 & 1 & 1 & 1 & 0 \\
Vidreiro & 0 & 0 & 0 & 0 & 1 & 1 & 0 \\
& & & & & & &
\end{tabular}

Fonte: dados primários (2017).

Observa-se que aqueles setores que a literatura aponta como tradicionalmente ativos, como no caso dos setores metalúrgico, bancário e petroquímico (CARVALHO NETO, 2001), marcam presença. Todavia não há uma predominância desses setores, de tal sorte que, como pode ser observado, há uma grande dispersão entre setores, sendo o setor dos eletricitários o com maior quantitativo de cláusulas vigentes no período, levemente maior que de outros setores. Destaca-se que os setores que obtiveram maior crescimento do número de cláusulas no período foram o metalúrgico, de telefonia e telemarketing, que são setores atuantes (CARVALHO NETO, 2001). Ressalta-se que a atuação dos sindicatos frente ao assédio moral, embora ainda carente, é de grande importância para a inibição da violência e de proteção ao trabalhador (FABRO; MAEHLER, 2015).

Outro objeto de análise foram as cláusulas que abordavam conjuntamente o assédio sexual. O assédio sexual consiste em uma forma de violência com histórico e literatura diversa referente ao assédio moral, remetendo aos estudos feministas da década de 1960, consistindo em um tipo mais visível e agressivo de violência no ambiente de trabalho, manifestado principalmente, segundo Hirigoyen (2006), por propostas ou ações de cunho sexual. Nesse sentido, cláusulas como "As empresas se obrigam a informar seus REAd | Porto Alegre - Vol. 24 - No 3 - Setembro / Dezembro 2018 - p. 21-45 
trabalhadores que não será admitida nenhuma prática de assédio moral ou sexual", do sindicato de Telemarketing de São Paulo, foram levantados, de tal forma que em 2011 haviam 9 cláusulas, 13 em 2012, 14 em 2013, 15 em 2014 e 12 em 2016. Ocorreu, no período, uma evolução contínua de cláusulas que abordam de modo específico a questão da violência sexual. $\mathrm{O}$ assédio sexual, em geral, tem como alvo preferencial as mulheres (FREITAS, 2001; HIRIGOYEN, 2006). Motivado, principalmente pela crescente inserção das mulheres no ambiente laboral, a qual modificou o status quo das organizações e "sacudiu" o universo machista das organizações, que observavam as mulheres como inferiores aos homens e incapazes de assumirem cargos de responsabilidade (HIRIGOYEN, 2006; CORREA; CARRIERI, 2007; OLIVEIRA; GAIO; BONACIM, 2009). Ou seja, trata-se de relações desiguais de gênero, e também pela relação de poder que um dispõe para penalizar o outro.

Levantaram-se também as cláusulas que previam o estabelecimento de programas, palestras e outros meios educativos para orientar os trabalhadores das empresas e prevenir práticas de assédio dentro das organizações. A prevenção constitui braço importante do combate a este tipo de violência, juntamente com a apuração e punição de casos. Nesse sentido, foram levantadas cláusulas, como a do sindicato dos Comerciários de Fortaleza, Ceará, que descreve "palestras aos comerciários sobre o assédio moral e sexual, e prevenção da AIDS e outros tipos de doenças endêmicas ou epidêmicas". Foram identificadas 13 cláusulas em 2011, 21 em 2012, 22 em 2013, 22 em 2014, 19 em 2015 e 12 em 2016. Após um aumento de 2011 para 2013, o quantitativo de cláusulas se manteve estável durante o período, com uma leve queda em 2015. Para Nunes e Tolfo (2012b), a informação sobre o que é o assédio, suas características, onde denunciar e demais assuntos, são aspectos fundamentais que auxiliam na prevenção e combate à violência. Para os autores, a informação evita a banalização do tema, muito comum nos dias atuais, tornando assim, o tema conhecido perante os trabalhadores e gestores.

Outro ponto de análise foi às cláusulas que previam a criação ou manutenção de conselhos ou comissões internas para tratar de casos de assédio moral dentro do estabelecimento empresarial. Assim, cláusulas como "As denúncias de casos de assédio sexual e assédio moral deverão ser feitas à Direção da Empresa, para a devida análise, encaminhamento e indicação, conforme o caso, de comissão de apuração, que deverá ser instaurada no prazo máximo de 30 dias, a contar da data do recebimento da denúncia" do sindicato dos profissionais de Processamento de Dados PRODEPA, do estado do Pará, foram contabilizadas. Em 2011 haviam 7 cláusulas, em 2012 haviam 9, em 2013 haviam 9, em 2014 
haviam 10 cláusulas, em 2015 haviam 10 e em 2016 haviam 2. Nota-se um pequeno aumento dentro do período.

Todavia, ressalta-se que a existência de órgão dentro da empresa não significa a participação dos sindicatos na apuração dos casos de violência. Para uma participação concreta, é necessário que o sindicato se insira efetivamente nos trabalhos dessas comissões, para garantir a imparcialidade do processo (LUNA, 2003). O estabelecimento de comissões com maior ou menor prescrição de funcionamento, inclusive paritárias, o que dá ao sindicato o poder de veto, sendo um avanço bem mais claro em relação ao mero discurso de boas intenções. Sindicato e empresa se obrigam a reunir, ficando muito mais fácil a atuação sindical para pressionar a empresa a agir em caso de assédio. Assim, foram levantadas aquelas que estabeleciam algum tipo de participação sindical nos processos de instituição dessas comissões, como na do sindicato dos Jornalistas de Belo Horizonte, em Minas Gerais, que dispõe "Cada Empresa deverá, dentro do prazo de 30 dias, contados da data da assinatura da presente Convenção Coletiva de Trabalho, constituir uma Comissão de Ética, a ser composta no máximo por 4 pessoas, sendo 02 por ela indicadas e as outras 02 indicadas pelo sindicato profissional e que terá por objetivo apurar denúncias de assédio moral que venham a surgir dentro da empresa. A Comissão, uma vez constituída, elaborará um "Regimento Interno para suas atividades". Nesse sentido, haviam 4 cláusulas em 2011 e 2012 e 3 cláusulas de 2013 a 2015. Observa-se que o quantitativo, levando-se em conta que o DIEESE tem mais de 700 sindicatos filados, é muito pequeno, e não houve crescimento de fato, o que pode estar apontando para uma falta de interesse sindical em adentrar nas discussões concretas sobre os casos de assédio moral, pelo menos pela via das comissões paritárias.

Um trabalho de apuração dos casos deve ser complementado pela previsão de punição aos assediadores. Desta maneira, verificou-se a previsão expressa de punição a autores de assédio moral nas empresas, como no caso do sindicato dos Trabalhadores Rurais da hortifruticultura de Juazeiro, na Bahia, que descreve que "Será vedado qualquer tipo de discriminação para permanência no emprego, comprometendo-se os empregadores a punir os seus empregados que, comprovadamente, sejam agentes de assédio sexual e moral". Em 2011 haviam 5 cláusulas, 6 em 2012, 8 em 2013, 7 em 2014 e 2015 e 5 em 2016. Nota-se, também, que há pouca preocupação com o estabelecimento de cláusulas punitivas expressas, bem como uma manutenção do quantitativo. A visualização de que medidas punitivas estão sendo aplicadas para aqueles que cometem o assédio moral ou outra violência dentro da organização, proporciona além da inibição de determinados comportamentos hostis, a percepção que a justiça está sendo feita (NUNES; TOLFO, 2012b). Para os autores, a 
punição para os agressores faz com que aqueles que foram de alguma forma alvos de hostilidades se sintam amparados pela organização em denunciar a violência sofrida.

Outras cláusulas analisadas foram aquelas que previam o apoio à vítima de assédio. Esse talvez seja o tópico mais negligenciado, haja vista o pequeno quantitativo de cláusulas tratando especificamente deste tema. Foi detectada 1 cláusula em 2011, 2 de 2012 a 2014 e 3 em 2015 e 2016, sendo elas elaboradas pelos sindicatos dos Correios, de caráter Nacional, dos empregados de Processamento de Dados da PRODEPA e dos empregados de Telecomunicação de São Paulo, que previam, respectivamente, que "Havendo a comprovação da denúncia ou em não se constatando os fatos denunciados, em ambos os casos, as vítimas, se solicitarem, receberão orientação psicológica pertinente", "Havendo a comprovação da denúncia ou em não se constatando os fatos denunciados, em ambos os casos, as vítimas receberão orientação psicológica adequada, e o empregado que efetuar o assédio será punido, nos termos da CLT" e "Fica ajustado ainda, caso seja configurado assédio moral ou sexual, a obrigação das empresas prestarem total apoio ao trabalhador assediado, através da devida assistência, resguardando sempre o direito do trabalhador submetido ao ato, tomar as medidas legais que julgue cabível". Nesse sentido, como se tratam de casos quase singulares, um estudo aprofundado desses casos poderia indicar a efetividade do apoio dado às vítimas, bem como demonstrar caminhos a serem trilhados por sindicatos em trabalhos futuros. No que tange ao suporte psicológico a vítima de assédio, Albanaes et al. (2017) relatam que devido a centralidade que o trabalho exerce na vida do indivíduo e a gravidade das situações hostis vivenciadas e suas consequências, a intervenção psicológica com a vítima é de grande importância para o estabelecimento de sua saúde e centralização. Para as autoras, a construção de diferentes estratégias de enfrentamento favorece a construção de projetos futuros e o fortalecimento psíquico dos alvos, que se encontram fragilizados em decorrência de suas experiências.

Quanto à ingerência sindical em casos de assédio moral, não foi encontrada cláusula em 2011, 1 de 2012 a 2014 e 2 em 2015 e 2016, figurando novamente o sindicato dos Correios e dos empregados de Telecomunicação de São Paulo, que estabeleciam que "As denúncias de casos de assédio sexual e de assédio moral deverão ser feitas pelo próprio empregado à área de Gestão das Relações Sindicais e do Trabalho, para a devida análise e encaminhamento, conforme o caso, ao grupo de trabalho responsável pela apuração. $\mathrm{O}$ empregado poderá solicitar o apoio da entidade sindical" e " $§ 1^{\circ}$ - A denúncia de assédio moral ou assédio sexual deverá ser efetuada por trabalhador devidamente identificado, pela entidade sindical ou de forma anônima; as empresas deverão proceder a averiguação no prazo 
máximo de 15 dias da data do recebimento da denúncia. $\S 2^{\circ}$ - Fica convencionado que toda e qualquer denúncia/resposta encaminhada as partes (empresa/Sintetel) será devidamente formalizada por meio de correspondência específica, mantendo-se o sigilo cabível”. Essa previsão demonstra a singularidade desse sindicato, que, conforme os dados indicam, incorporou em sua pauta de fato a bandeira do combate ao assédio moral.

\section{CONSIDERAÇÕES FINAIS}

Em primeiro lugar, destaca-se que, apesar dos danos que o assédio moral pode causar no bem-estar dos trabalhadores, a atuação sindical ainda é bastante reduzida (BARRETO, 2006), haja vista que em um universo de mais de 700 entidades sindicais e mais de 200 categorias profissionais, em que a maior parte firma acordos e convenções coletivas de trabalho, poucas delas dedicaram atenção à questão ao ponto de consagrá-la em cláusulas específicas.

Mesmo assim, observou-se no período entre 2011 e 2013 um crescimento no número de cláusulas, todavia acompanhado por crescimento daquelas do tipo genérico, em que não é estabelecido nenhum tipo de ação concreta para prevenir ou coibir esse tipo de violência.

Por outro lado, em diversas cláusulas levantadas, nota-se uma atenção maior à questão da prevenção, por meio do estabelecimento de cláusulas que prescrevem programas, palestras e outros meios educativos com esta finalidade. No universo dessas cláusulas, nota-se que a questão do assédio sexual também é destacada.

O estabelecimento de comissões paritárias, dando ao sindicato o poder de veto, é um avanço bem mais claro em relação ao mero discurso de boas intenções. Sindicato, com poder de veto e empresa obrigada a reunir são condições para concretizar a luta contra o assédio.

Outro achado alvissareiro da pesquisa foi a existência de cláusulas que previam meios efetivos de atuação sindical frente ao apoio a vítimas e inferência na apuração de denúncias são tratados. Esta é uma contribuição significativa deste trabalho, uma vez que o apoio às vítimas é negligenciado pela literatura.

Pode-se dizer, de toda forma, que as cláusulas de acordos e convenções coletivas se apresentam como instrumentos importantes para a prevenção, intervenção e combate ao assédio moral. E demonstra, mesmo tímida, a atuação sindical na defesa do bem-estar, saúde e segurança do trabalhador, que no momento da violência se encontra desamparado e fragilizado. Diante do contexto atual de competitividade e busca pela produtividade, cabe ao sindicato cada vez mais lutar por aqueles que ele representa.

REAd | Porto Alegre - Vol. 24 - No 3 - Setembro / Dezembro 2018 - p. 21-45 
Pode-se concluir que há algumas luzes no fim do túnel em relação ao tratamento do assédio nas negociações coletivas entre trabalhadores e empregadores. Destacamos que alguns casos já procuram partir para ações concretas, e não ficam apenas no mero discurso inerte, em que prejudica principalmente a vítima de tal violência.

Por fim, este trabalho possui como lacunas a serem investigado por pesquisas futuras a efetividade dessas cláusulas na atuação sindical dos respectivos sindicatos, a falta de interesse de grande parte dos sindicatos em tratar o tema e os resultados dessa atuação quando comparado com sindicatos que não possuem interesse na temática.

\section{REFERÊNCIAS}

ALBANAES, P. et al. Intervenção em grupo de apoio psicológico a trabalhadores vítimas de assédio moral. Revista de Psicología, Lima, n. 35, v. 1, p. 61-96, 2017.

ANTUNES, R.; DRUCK, M. G. A terceirização sem limites: A precarização do trabalho como regra. O Social em Questão, n. 34, p. 19-40, 2015.

ARAÚJO, A. R. As metas e o assédio moral organizacional: do sequestro da subjetividade ao resgate da cidadania. In: Congreso Iberoamericano sobre Acoso Laboral e Institucional, 3., 2017, Florianópolis. Anais... Florianópolis: UFSC, 2017. p. 110-127.

AZEVEDO, M. C.; TONELLI, M. J.; SILVA, A. L. Contratos flexíveis de trabalho: diferentes perfis de trabalhadores qualificados brasileiros. Revista de Administração (São Paulo), São Paulo, n. 50, v. 3, p. 277-291, 2015.

BARRETO, M. Violência, saúde e trabalho: uma jornada de humilhações. São Paulo: EDUC, 2006.

BAUER, M. W. Análise de conteúdo clássica: uma revisão. In: BAUER, Martin W.;

GASKELL, George (Org.). Pesquisa qualitativa com som, imagem e texto. $2^{\mathrm{a}}$ ed. Vozes, Petrópolis, 2003. p. 189-221.

BOMBONATI, R. Uberização: Estágio avançado da flexibilização das Relações de Trabalho. Revista de Economia Política e Pensamento Crítico, São Paulo, n. 3, v. 2, p. 11-39, 2017. BRADASCHIA, C. A. Assédio moral no trabalho: a sistematização dos estudos sobre um campo em construção. 2007. 230f. Dissertação (Mestrado em Administração de Empresas) Programa de Pós-Graduação em Administração de Empresas, Fundação Getúlio Vargas, São Paulo, 2007.

CAMPOS, A. G. Sindicatos no Brasil: o que esperar no futuro próximo?. Brasília: Ipea, 2016.

REAd | Porto Alegre - Vol. 24 - No 3 - Setembro / Dezembro 2018 - p. 21-45 
CARDOSO, A. M. Dimensões da Crise do Sindicalismo Brasileiro. Caderno CRH, Salvador, n. 28, v. 75, p. 493-510, 2015.

CARVALHO NETO, A. M. Relações de Trabalho e Negociação Coletiva na Virada do Milênio: estudo em quatro setores dinâmicos da economia brasileira. Petrópolis: Vozes, 2001.

CARVALHO NETO, A. M.; AMORIM, W. A. C.; FISCHER, A. L. Top Human Resources Managers Views on Trade Union Action in Brazilian Corporations. Brazilian

Administration Review, Rio de Janeiro, n. 13, v. 4, p. 1-23, 2016.

CASTELLS, M. A sociedade em rede. São Paulo: Paz e Terra, 1999.

CORREA, A. M. H.; CARRIERI, A. P. Percurso semântico do assédio moral na trajetória profissional de mulheres gerentes. Revista Administração de Empresas, São Paulo, n. 47, v. 1, p. 22-32, 2007.

COSTA, H. Redes sindicales de trabajadores. Nueva Sociedad, Buenos Aires, n. 264, p. 111$124,2016$.

COSTA, M. S. O Sistema de Relações de Trabalho no Brasil: alguns traços históricos e sua precarização atual. Revista Brasileira de Ciências Sociais, São Paulo, n. 20, v. 59, p. 111$131,2005$.

CRUZ, M. V. G.; SARSUR, A. M.; AMORIM, W. A. C. Gestão de competências nas relações de trabalho: o que pensam os sindicalistas?. Revista de Administração Contemporânea, Rio de Janeiro, n. 16, v. 5, p. 705-722, 2012.

DIEESE. A Reforma Trabalhista e os impactos para as relações de trabalho no Brasil. São Paulo: DIEESE, maio 2017a. (Nota Técnica, 178)

DIEESE. Relações de trabalho sem proteção: de volta ao período anterior a 1930. São Paulo: DIEESE, maio 2017b. (Nota Técnica, 179).

DIEESE. Riscos e perdas impostos pelo PL 6.787/2016 aos trabalhadores e ao movimento sindical. DIEESE, maio 2017c. (Texto-síntese).

DUNLOP, J. T. Industrial Relations Systems. Boston, Mass: Harvard Business School, 1993. $400 \mathrm{p}$.

EINARSEN, S.; HOEL, H. Bullying and mistreatment at work: How managers may prevent and manage such problems. In: KINDER, A.; HUGHES, R.; COOPER, C. L. (Comps.). Employee well-being support: A workplace resource New York: John Wiley and Sons Ltd, 2008. p. 161-173

REAd | Porto Alegre - Vol. 24 - No 3 - Setembro / Dezembro 2018 - p. 21-45 
EINARSEN, S. et al. Workplace Bullying: individual pathology or organizational culture? In: BOWIE, V.; FISCHER, B. S.; COOPER, C. L. (Eds.). Workplace Violence: issues, trends, strategies. Devon: Willian Publishing, 2005. p. 229-247.

EINARSEN, S. et al. The concept of bullying and harassment at work: the European tradition. In: EINARSEN, S. et al. (Orgs.). Bullying and Harassment in the Workplace: Developments in Theory, Research, and Practice. London: Taylor \& Francis, 2011. p. 3-39. FABRO, A. C.; MAEHLER, C. Combate ao assédio moral no trabalho: identificando medidas adotadas pelas organizações sindicais de SC. In: EMMENDOERFER, M. L.; TOLFO, S. R.; NUNES, T. S. (Org.). Assédio moral: em organizações públicas e a (re)ação dos sindicatos. 1. Ed. Curitiba, PR: ed. CRV, 2015. p. 215-228.

FREITAS, M. E. Assédio moral e assédio sexual: faces do poder perverso nas organizações. Revista de Administração de Empresas, São Paulo, n. 41, v. 2, p. 8-19, 2001.

FREITAS, M. E. Quem paga a conta do assédio moral no trabalho? RAE-eletrônica, São Paulo, n. 6, v. 1, p. 1-7, 2007.

GONÇALVES, W. J. Discriminação contra a mulher obesa e assédio moral genérico: tutela efetiva da igualdade no processo de reversibilidade de conduta uma questão de direitos fundamentais. Desafio: Revista de Economia e Administração, São Paulo, n. 10, v. 22, p. 67-82, 2009.

GUIMARÃES, S.; CARVALHO NETO, A. O futuro dos sindicatos. Estudo sobre sindicatos de telecomunicações no Brasil. Caderno CRH, Salvador, n. 19, p. 277-291, 2006.

HARRINGTON, S.; WARREN, S.; RAYNER, C. Human Resource Management practitioners' responses to workplace bullying: Cycles of symbolic violence. Organization, London, n. 22, v. 3, p. 368-389., 2015.

HELOANI, R. Assédio moral - Um ensaio sobre a expropriação da dignidade no trabalho. RAE-eletrônica, São Paulo, n. 3, v. 1, p. 1-8, 2004.

HELOANI, R.; BARRETO, M. Assédio moral: gestão por humilhação. Curitiba: Juruá, 2018.

HIRIGOYEN, M-F. Mal-estar no trabalho: redefinindo o assédio moral. 3. ed. Rio de Janeiro: Bertrand Brasil, 2006.

KATZ, H. Is U.S. public sector labor relations in the midst of a transformation? Industrial and Labour Relations Review, New York, n. 66, v. 5, p. 1031-1046, 2013.

KAUFMAN, B. E. The Theoretical Foundation of Industrial Relations and Its Implications for Labour Economics and Human Resource Management. Industrial and Labour Relations Review, New York, n. 64, v. 1, p. 74-108, 2010. 
KAUFMAN, B. E.; BARRY, M. IR Theory Built on the Founders' Principles with Empirical Application to Australia. Industrial and Labour Relations Review, New York, n. 67, p. 1203-1234, 2014.

KREIN, J. O desmonte dos direitos, as novas configurações do trabalho e o esvaziamento da ação coletiva: consequências da reforma trabalhista. Tempo Social, v. 30, n. 1, p. 77-104, 26 abr. 2018.

LUNA, M. Acoso psicológico en el trabajo (mobbing). Madri: Ediciones GPS Madri.

Relatório preparado para a Secretaria de Salud Laboral de CC.OO, 2003.

NUNES, T. S.; TOLFO, S. R. Assédio moral no trabalho: consequências identificadas por servidores docentes e técnico-administrativos em uma universidade federal brasileira.

Revista Gestão Universitária na América Latina - GUAL, Florianópolis, n. 5, v. 3, p. 264286, 2012a.

NUNES, T. S.; TOLFO, S. R. Políticas y prácticas de prevención y combate al acoso moral en una universidad brasileña. Salud de los Trabajadores, Carabobo, n. 20, v. 1, p. 61-73, $2012 b$.

NUNES, T. S.; TOLFO, S. R. (2013a). A dinâmica e os fatores organizacionais propiciadores à ocorrência do assédio moral no trabalho. Revista de Gestão e Secretariado - GeSec, São Paulo, n. 4, v. 2, p. 90-113, 2013a.

NUNES, T. S.; TOLFO, S. R. Assédio Moral em Universidade: as possíveis consequências em comentar e/ou denunciar a violência. Administração Pública e Gestão Social, Viçosa, n. 5, v. 4, p. 148-155, 2013b.

NUNES, T. S.; TOLFO, S. R. O assédio moral no contexto universitário: uma discussão necessária. Revista de Ciências da Administração, Florianópolis, n. 17, v. 41, p. 21-36, 2015.

OFFE, C. Trabalho: a categoria-chave da sociologia? Revista Brasileira de Ciências Sociais, São Paulo, n. 10, v. 4, p. 13-41, 1989.

OLIVEIRA, A. R.; GAIO, L. E.; BONACIM, C. A. G. Relações de gênero e ascensão feminina no ambiente organizacional: um ensaio teórico. Revista de Administração da UFSM, Santa Maria, n. 2, v. 1, p. 80-97, 2009.

PIORE, M. J. Whither Industrial Relations: Does it Have a Future in Post-Industrial Society?

British Journal of Industrial Relations, London, n. 49, v. 4, p. 792-801, 2011.

PORTO, R. G.; CARVALHO NETO, A. O Esvaziamento da noção do ser coletivo e a reação sindical no Brasil do século XXI. In: Encontro de Gestão de Pessoas e Relações de Trabalho, 3., 2011, João Pessoa. Anais... João Pessoa, EnGPR, 2011. p. 1-17.

REAd | Porto Alegre - Vol. 24 - No 3 - Setembro / Dezembro 2018 - p. 21-45 
SALIN, D. Workplace Bullying among Business Professionals: Prevalence, Organisational Antecedents and Gender Differences. Doctoral dissertation. Research Reports, Serie A, no 117. Helsinki: Swedish School of Economics and Business Administration, 2003.

SARAIVA, L. A. S.; FERREIRA, J. A.; COIMBRA, K. E. R. Relações de trabalho em empresas terceirizadas sob a ótica dos trabalhadores: um estudo no setor de mineração.

Revista Gestão Organizacional, Chapecó, n. 5, v. 2, p. 134-148, 2012.

SCANFONE, L.; TEODÓSIO, A. D. S. S. Assédio moral nas organizações: novas roupagens para uma antiga temática? Revista Economia \& Gestão, Belo Horizonte, n. 4, v. 7, p. 71-80, 2004.

SOYLU. S.; SHEEHY-SKEFFINGTON. J. Asymmetric intergroup bullying: The enactment and maintenance of societal inequality at work. Human Relations, London, n. 68, v. 7, p. 1099-1129, 2015.

TAPIA, M; IBSEN, C. L.; KOCHAN, T. A Mapping the frontier of theory in industrial relations: the contested role of worker representation. Socio-Economic Review, Oxford, n. 13, v. 1, p. 157-184, 2015.

TARCITANO, J. S. C.; GUIMARAES, C. D. Assédio moral no ambiente de trabalho.

Trabalho de Conclusão do Curso de Tecnologia em Gestão de Recursos Humanos: Centro de Educação Tecnológica Estácio de Sá, Juiz de Fora, 2004.

TOLFO, S. R.; SILVA, N.; KRAWULSKI, E. Acoso laboral: relaciones con la cultura organizacional y la gestión de personas. Salud de los Trabajadores, Carabobo, n. 21, v. 1, p. $5-18,2013$.

VASCONCELOS, Y. L. Assédio moral nos ambientes corporativos. Cadernos EBAPE.BR, Rio de Janeiro, n. 13, v. 4, p. 821-851, 2015.

YIN, R. K. Estudo de caso: planejamento e métodos. 2. Ed. Porto Alegre: Bookman, 2005. 